\title{
A Study of the Influence of Chinese language and Culture on Second Language Communicative Competence Acquisition
}

\author{
Dongmei Li, Xiaoxiao Mao \\ Foreign Languages Department, Beihua University Jilin, Jilin China, 132013, China
}

Keywords: Chinese language and culture; language transfer; second language communicative competence.

\begin{abstract}
Second language acquisition is the process by which people develop proficiency of a second or foreign language. Native language may unavoidably play a function in this process. In this thesis, the author discusses the results of the study on the influence of language transfer on the communicative competence in second language acquisition process from the perspective of listening, speaking, reading and writing with the hope of providing theoretical and practical help for second language teaching and learning. This paper is about the achievement of "The research into the second language acquisition process from the perspective of Chinese transfer" subsidized by Education Department of Jilin Province.
\end{abstract}

D.H. Hymes, an American sociolinguist, believes that the nature of a language is its social communicative function.

Practically speaking, communicative competence refers to learners' ability to use the target language to listen, speak, read, and write for the purpose of expressing their ideas. With the development and opening up of China, acquiring the second language communicative competence has become more and more learners' goal of learning a language. In China most learners' native language is Chinese, English is their foreign language. It's unavoidable for them to be influenced by their native language and culture in the process of acquiring communicative competence of English. Odlin called it language transfer. To him language transfer is the cross-linguistic influence due to the similarity and difference between the target language and the acquired (or not fully acquired) language. Its influence may be either positive or negative which is reflected in the learners' process of acquiring the communicative competence of using the target language to listen, speak, read, and write.

\section{The influence of Chinese language and culture on the acquisition of second language listening competence}

The process of listening comprehension is the process of listening decoding. In decoding, language transfer takes place also. The positive transfer of Chinese in listening usually exists in the following aspects.

1) Transfer of language and culture

In listening comprehension, the learners achieve information decoding with the help of the existing background knowledge, namely, the learners' knowledge about native language and culture. The positive transfer may happen when the listener feels that there is similarity between the input information and the existing background knowledge of Chinese language and culture.

2) Transfer of pragmatic inference

In listening, the listener can make sure the intention of the speaker according to the linguistic context of the listening materials. The linguistic context not only includes the context of exchange and the immediate physical environment, but also the knowledge elements of the listeners. Thus the process of decoding the listening information is the process of transfer from the known information (context knowledge) to listening comprehension prediction.

3) Transfer of cognitive pattern 
The cognitive pattern of the native language may give rise to the positive transfer in listening comprehension. The contents of listening comprehension materials are mostly about daily life. The mutual experience of different language users are unavoidably reflected in language and culture. In the process of decoding, the listener may speed up his listening comprehension by making use of the superposition of cognitive environment between Chinese and English. For example, though the listener didn't hear clearly the word before in the sentence Please lock the door before leaving., he can still guess its meaning according to the native language cognitive patter.

Of course some factors like the deletion of liaison, the indiscrimination of voiceless and voiced sound, the high frequently use of simple sentences in Chinese, the non-correspondence and difference of phoneme combination between Chinese and English language lead to the negative transfer which makes listening more difficult.

\section{The influence of Chinese language and culture on the acquisition of second language speaking competence}

The influence of Chinese language and culture on the acquisition of second language speaking competence may be multi-aspected. This paper just focuses on discourse and cultural pragmatics.

1. Transfer of discourse

The transfer of discourse is mainly seen in request and apology.

(1)Request

Chinese language users usually express their requests directly. For instance, The English native speakers intend to use model verbs and interrogative sentences to express request for the purpose of being polite. For example, Would you please close the door. This mode of behavior may leave an impression of hypocrisy upon the Chinese people.

(2)Apology

The transfer of apology chiefly takes place in the frequency of use idiomatic expression of apology and in dealing with the relationship between apology and other speech act. The frequency of apology of Chinese native speakers is much less that of the English native speakers. In addition the difference of the relationship between apology and other speech act between Chinese and English may also lead to wrongly use of idiomatic expression. Take the sentence as an example. It is usually wrongly expressed as I'm sorry, is anybody sitting here? But the correct sentence should be Excuse me, is anybody sitting here?

2. Transfer of cultural pragmatics

As far as Kasper (1992:207) is concerned pragmatic transfer is the influence of the learners' native language pragmatic knowledge upon their comprehension, output and second language pragmatic knowledge learning. Pragmatic transfer can be classified into two types. They are pragmatic transfer and social pragmatic transfer. The former refers to the facts that the speakers use the equivalent words which belong to the second language in syntax and semantics to express implication and politeness. Let's take the words used by learners who do not catch what is said by the others as an example:

A; Excuse me, how can I get to Jiangnan bookstore?

B: What? Repeat please!

Obviously in these sentences, what is used in B's words is Chinese communicative and pattern. Though it plays the function of asking the speaker to repeat what did he/she say, it also leaves upon the English native speakers the impression of being impolite.

Social pragmatic transfer refers to the practice of the speaker copy the personal understanding of social distance, power, rights, obligation, requirements of different speech acts and the contextual elements that influence discourse participation relationship in native language to second language. It results from the second language learners' use of native social pragmatic rules or norms which can not be accepted by the others. The social pragmatic transfer can be seen in the speech acts like addressing, greetings, topic selection, invitation, congratulations, showing modesty, offering help, and parting etc.. Chinese people are well known for their hospitality. Regardless of the liking or disliking of the invited, the host will make an invitation repeatedly to the extend of imposing. It seems 
that only in this way can he show his sincerity and enthusiasm. But in English culture, people think highly of individualism and freedom. Personal will of others is concerned very much in invitation. Words like Please come if you like and such are usually said by the inviter without imposing.

\section{The influence of Chinese language and culture on the acquisition of second language reading competence}

The English reading competence is bound to be influenced by the reader's Chinese reading habits, mode of think and reading strategies. The transfer of reading competence is represented by the mutual dependence hypothesis of different language and language threshold hypothesis. According to the mutual dependence hypothesis of different language the native language reading competence of the readers may transfer to the second language reading competence development. In reading the reader makes hypothesis on the reading materials on the basis of his/her existing syntax and pragmatic knowledge and affirm or deny his/her hypothesis according to the clues got from the reading materials. Hereby we believe that those who are able in native language reading also demonstrate strong competence in second language reading.

As far as language threshold hypothesis is concerned, the native language reading competence can influence the second language reading only when the reader's second language level reach certain critical value. In reading if positive transfer of native language doesn't take place then negative transfer may happen and it is very likely that the native language doesn't play any function at all. After more than threshold, the obvious correlation between native language reading competence and the target language reading competence can be seen. Namely Chinese reading competence doesn't exert much influence upon English reading before the learner reach certain level of English. But after that the Chinese language level of the learners and their English level become ever-increasing with the improvement of i. In critical value of English the high level of reading skills like inference and induction are obviously influenced by Chinese language reading competence and the deficiency of Chinese language reading competence may influence the process of positive transfer.

In the process of acquiring reading competence the learners can achieve positive transfer by making use of the existing knowledge of Chinese language, culture, history and living background.

\section{The influence of Chinese language and culture on the acquisition of second language writing competence}

Chinese language and culture, just like a double-edged sword, plays both a positive and negative function in second language writing competence acquisition. That can be seen in the following three aspects.

1) Chinese vocabulary competence may cause the directive or indirective positive transfer in second language writing

Directive transfer refers to the directive influence of Chinese upon second language writing. The indirective transfer displays in three aspects. (1) Chinese vocabulary influences the second language writing through the medium of grammar; (2) Chinese vocabulary influences the second language writing through the Chinese writing; (3) Chinese vocabulary influences the second language writing through Chinese discourse and Chinese writing. Therefore the learners who are high in vocabulary level have certain advantage in second language writing. In addition, Sandra(1997) believes that second language vocabulary learning come true by contextualization of the new words and the existing Chinese or target language words. In this way Chinese promotes the second language vocabulary learning. And the vocabulary size can influence the richness of language in writing.

2) Chinese thinking competence has active effect on second language thinking competence

Some researchers found that those who have high native language level can don well in second language writing in terms of cohesion and coherence. The textual knowledge of Chinese may transfer to second language writing. The researchers, like Bosher(1998), Cumming (4989), Raines(1985), and Zamel (1982) found in their research that the habit of native language thinking may transfer into 
second language writing no matter how high or how low a learner's second language level is. Laly (1988) put forward eight functions of native language thinking mode in second language writing. They are (1)conceive related content,(2)self-question,(3)organize complex thoughts,(4)recall past experience,(5)evaluate the text structure,(6)improve the productive competence, (7) increase the variety of language, and (8) reflect cultural sensitivity.

It is proved by practice that most learners who have strong ability in second language writing also have strong native communicative competence. They are good at applying native language writing knowledge and mode of thinking to deal with the organization, the wording and the writing style in second language writing.

Of course, negative transfer of the Chinese also happens in second language writing.

1) The negative transfer with respect to vocabulary

In second language writing the articles may be misused even may not be used due to the absence of them in Chinese. Some learners may say "the internet's goods" because there is no grammatical category of case in Chinese and there is no inflection of possessive case in Chinese. And some learners can not make any difference between the singular and plural form of nouns in second language writing.

2) The negative transfer with respect to syntax

Some learner may make the sentence like "Good good study, day day up" by improper match of words and structure between Chinese and second language. The other common mistakes in second language writing as a result of negative transfer of Chinese is inconsistency in subject-predicate and tense, using of run-on sentences, omission of be in passive voice sentences.

3) The negative transfer with respect to discourse and mode of thinking

Influenced by Chinese mode of thinking and writing models, some learners expound their views by using abstract language with the help of inference in stead of linear thinking like the native speakers. Chinese is a parataxis language which achieves cohesion and coherence by means of semantic connection. On the other hand English, as a hypotaxis language, cohesion and coherence can by achieved by grammatical devices like coordinating conjunctions, relative pronouns as well as relative adverbs. There are many long and complex sentences in English. Under the influence of Chinese some learners are not used to using transitional words and conjunctions. And simple sentences are used every often.

\section{Conclusion}

In second language communicative competence acquisition Chinese language and culture areexploitable resources. They on the other hand are the obstacle of communicative competence acquisition. To increase efficiency of second language communicative competence acquisition, the learners need to fully understand the positive function of Chinese language and culture and overcome the negative transfer of them.

\section{References}

[1] Ellis, R. 1994.The Study of Second Language Acquisition [M]. London: Oxford University Press.

[2] Odlin, T. 1987..Language Transfer [M]. Cambridge: Cambridge University Pres.

[3] Odlin, T. 1989.Language Transfer Crosslinguistic Influence in Language Learning [M]. Los Angeles: University of California Press.

[4] Walter, C. 2004. Transfer of Reading Comprehension Skills to L2 is Linked to Mental Representation of Text and to L2 Working Memory [J]. Applied Linguistics. 